\title{
Resoluçāo estética através de procedimentos minimamente invasivos
}

Aesthetic resolution through minimally invasive procedures

Resolución estética através de procedimentos mínimamente invasivos

Vitoria Goncalves BEZERRA ${ }^{1}$

Lucas Akccyl Albuquerque ALVES ${ }^{1}$

Maria Arielly Costa TAVARES ${ }^{1}$

Maria Arianny Costa TAVARES ${ }^{1}$

Diala Aretha de Sousa FEITOSA ${ }^{2}$

${ }^{1}$ Acadêmico (a) do Curso de Odontologia do Centro Universitário Doutor Leāo Sampaio, UNILEÃO, 63040-405 Juazeiro do Norte - CE, Brasil

${ }^{2}$ Prof ${ }^{a}$. Doutora em Dentistica, Centro Universitário Doutor Leão Sampaio, UNILEÃO, 63040-405 Juazeiro do Norte - CE, Brasil

\section{Resumo}

Alterações de cor são uma das principais causas de insatisfação por parte dos pacientes, comprometendo a estética do sorriso. Estas denotam diversas etiologias e diferentes graus de comprometimento estético, que necessitam de tratamento específico ou associações. Desde procedimentos diretos como polimentos, microabrasão do esmalte, procedimentos clareadores e restaurações adesivas diretas, até mesmo através de procedimentos indiretos como facetas, lentes de contato e coroas. O estudo relata a resolução estética do manchamento dentário decorrente de fluorose através da associação de tratamentos minimamente invasivos. Para o caso, optou-se pela técnica de microabrasão do esmalte dental com ácido fosfórico $37 \%$ associado à pedra-pomes, no total de três sessões. E posteriormente o clareamento dental de consultório feito em duas sessões com o clareador Peróxido de Hidrogênio a 35\%. Quando bem indicada, a associação de tratamentos minimamente invasivos para remoção de manchas brancas decorrentes da fluorose dentária demonstra sucesso. Desta forma observou-se que a associação de tratamentos minimamente invasivos devolveu a paciente um sorriso estético, agradável e consequentemente melhorou a autoestima da mesma.

Descritores: Estética; Clareamento Dental; Microabrasão do Esmalte.

\section{Abstract}

Color changes are one of the main causes of patient dissatisfaction, compromising the aesthetics of the smile. These denote various etiologies and different degrees of aesthetic impairment, which require specific treatment or associations. From direct procedures such as polishing, enamel microabrasion, bleaching procedures and direct adhesive restorations, even though indirect procedures such as veneers, contact lenses and crowns. The study reports the aesthetic resolution of dental staining due to fluorosis through the association of minimally invasive treatments. For this case, we opted for the dental enamel microabrasion technique with $37 \%$ phosphoric acid associated with pumice, in a total of three sessions. And then the office dental bleaching had done in two sessions with the $35 \%$ hydrogen peroxide bleaching. When well indicated, the combination of minimally invasive procedures to remove white spots due to dental fluorosis is successful. Thus, it was observed that the combination of minimally invasive treatments returned the patient a pleasant, aesthetic smile and consequently improved her self-esteem.

Descriptors: Esthetics; Tooth Bleaching; Enamel Microabrasion.

\section{Resumen}

Los cambios de color son una de las principales causas de insatisfacción del paciente, ya que comprometen la estética de la sonrisa. Estos denotan diversas etiologías y diferentes grados de comprometimiento estético, que requieren un tratamiento específico o asociaciones. Desde procedimientos directos como pulido, microabrasión de esmalte, procedimientos de blanqueo y restauraciones adhesivas directas, incluso a través de procedimientos indirectos como carillas, lentes de contacto y coronas. El estudio informa la resolución estética de las manchas dentales debido a la fluorosis a través de la asociación de tratamientos mínimamente invasivos. Para este caso, optamos por la técnica de microabrasión del esmalte dental con ácido fosfórico al 37\% asociado con piedra pómez, en un total de tres sesiones. Y luego el blanqueamiento dental en el consultorio realizado en dos sesiones con el blanqueo con peróxido de hidrógeno al 35\%. Cuando está bien indicado, la combinación de tratamientos de eliminación de manchas blancas mínimamente invasivos debido a la fluorosis dental es exitosa. Por lo tanto, se observó que la combinación de tratamientos mínimamente invasivos le devolvió al paciente una sonrisa agradable y estética $\mathrm{y}$, en consecuencia, mejoró su autoestima.

Descriptores: Estética; Blanqueamiento de Dientes; Microabrasión del Esmalte.

\section{INTRODUÇÃO}

A coloração dos dentes é um fator de grande relevância para a estética dentária, muitos buscam a solução para essa desarmonia frente as exigências da sociedade quanto ao padrão de beleza, aumentando assim a procura de procedimentos estéticos e minimamente invasivos nos consultórios. Os manchamentos e alterações de cor dos dentes podem ter diversos tipos de etiologia, tanto intrínsecas que são relacionados a fatores sistêmicos como deficiência nutricional, ingesta de flúor durante a formação dental e genética ${ }^{1}$, como também as extrínsecas que estão relacionadas ao consumo de alimentos com alto teor de corantes, medicamentos e entre outros, podendo afetar ambas as dentições ${ }^{2}$.

Dentre algumas das alterações mais encontradas são a hipoplasia de esmalte, amelogênese imperfeita e fluorose dental, ambas apresentando características clinicas semelhantes como manchas branco leitoso, lisas e brilhantes de origem intrínseca, porém com tomadas de decisões de tratamentos diferenciadas, perante a isso é de suma importância que o profissional tenha conhecimento sobre essas alterações e com isso indicar a melhor opção de tratamento. Tratamentos invasivos como facetas diretas e indiretas e os tratamentos considerados minimamente invasisos como a microabrasão do esmalte e clareamento dental, em alguns casos podendo até mesmo associa-los para melhor resultado ${ }^{3}$.

A microabrasão consiste na remoção dos manchamentos mais superficiais do esmalte dental de forma definitiva e com o mínimo de desgaste de estrutura, é feito com a associação de ácido fosfórico $37 \%$ e um agente abrasivo como a pedra pomes ${ }^{2}$. O clareamento dental é indicado para manchamento mais generalizado e de origem extrínseca, podendo ser a técnica caseira ou de consultório ${ }^{1}$.

No caso clínico apresentado a paciente tinha 
como queixa principal o manchamento dental e insatisfação devido a coloração amarelada dos dentes, assim foram realizadas sessões de microabrasão associada ao clareamento de consultório que solucionou a problemática e assim devolvendo a estética do sorriso e consequentemente aumentando a auto estima da paciente.

\section{CASO CLÍNICO}

Paciente do gênero feminino, 21 anos procurou atendimento odontológico com queixa principal de "manchas brancas nos dentes e insatisfação com a cor" (Figura 1).

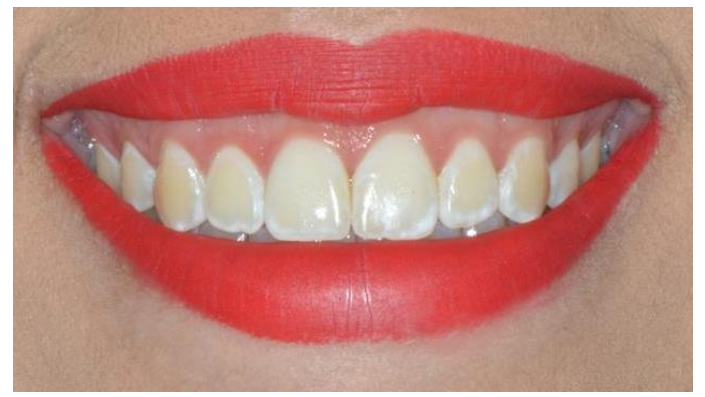

Figura 1: Aspecto clínico inicial.

A mesma relatou que sentia-se envergonhada ao sorrir quando ia tirar uma foto, tipo uma "selfie". Ao exame clinico inicial a paciente não apresentou cárie ou doença periodontal e foi diagnosticada com fluorose dental com severidade leve grau 3 na classificação Dean, apresentando manchas brancas opacas bem evidentes nas bordas incisais e ameias de todos os dentes e restritas ao esmalte ${ }^{4}$. No plano de tratamento optou-se pela técnica de microabrasão do esmalte dental e posteriormente clareamento dental de consultório. A técnica de microabrasão do esmalte dental usada no caso foi realizada com ácido fosfórico $37 \%$ associado a pedra pomes de granulação extra fina, com proporções volumétricas iguais 5 . Após a profilaxia com pedra pomes e água foi realizado o isolamento, protegendo a gengiva do paciente do sistema microabrasivo (Figura 2). Em seguida foi feito a manipulação da pasta abrasiva com proporção volumétrica iguais de ácido fosfórico $37 \%$ (Condac®), FGM Produtos odontológicos, Joinville, SC, Brasil) e pedra pomes extrafina (Maquira®; Produtos odontológicos, Maringá, PR, Brasil). A aplicação da pasta abrasiva foi realizada com a taça de borracha em movimentos intermitentes sobre a mancha do esmalte (Figura 3 ).

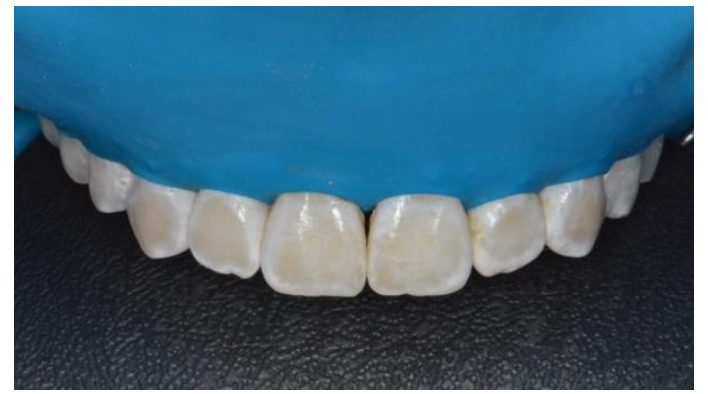

Figura 2: Aspecto clínico após isolamento absoluto do campo operatório.

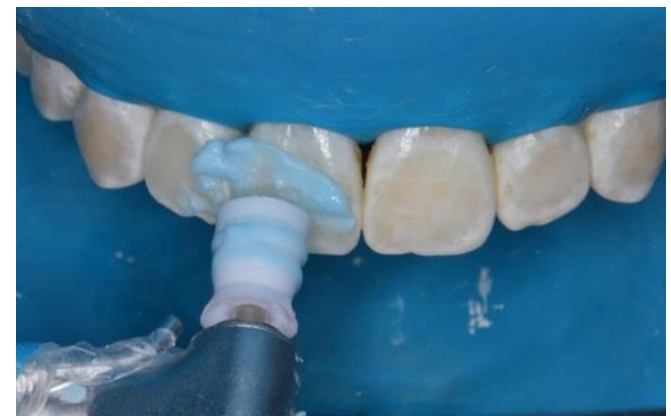

Figura 3: Aplicação da pasta (ácido fosfórico 37\% + pedra-pomes).

Foram realizadas três sessões, sendo em média sete aplicações de dez segundos em cada elemento dentário, seguido de lavagem abundante. Ao final de cada sessāo foi realizado polimento com disco de feltro impregnado com pasta diamantada (Polimax ${ }^{\circledR}$, TDV Produtos odontológicos, Pomerode, SC, Brasil) (Figura 4) e aplicação tópica de flúor neutro 2\% (Iodontosul®; Produtos odontológicos, Porto Alegre, RS, Brasil) (Figura 5). A remoção das manchas após as sessões de microabrasão podem ser observadas nas Figuras 6 e 7. O clareamento dental de consultório, no total de duas sessões, com o gel clareador peróxido de hidrogênio a 35\% (Whiteness HP®; FGM Produtos odontológicos, Joinville, SC, Brasil) foi realizado 15 dias após a última sessão de microabrasão.

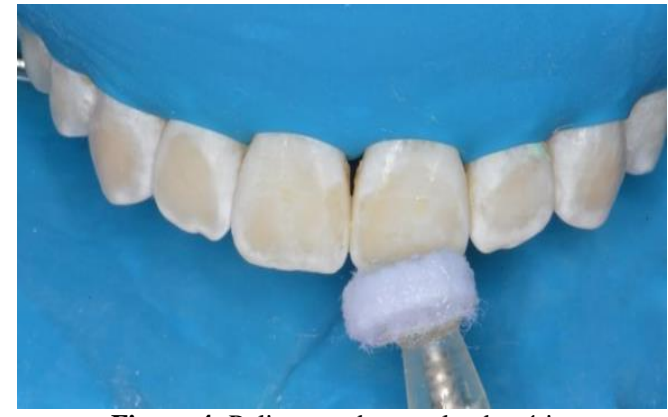

Figura 4: Polimento do esmalte dentário.

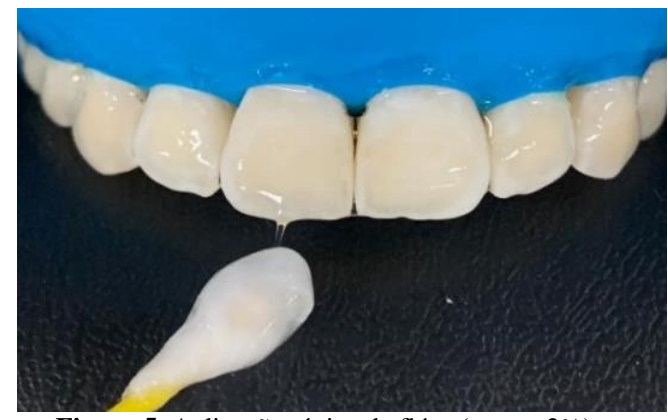

Figura 5. Aplicação tópica de flúor (neutro 2\%).

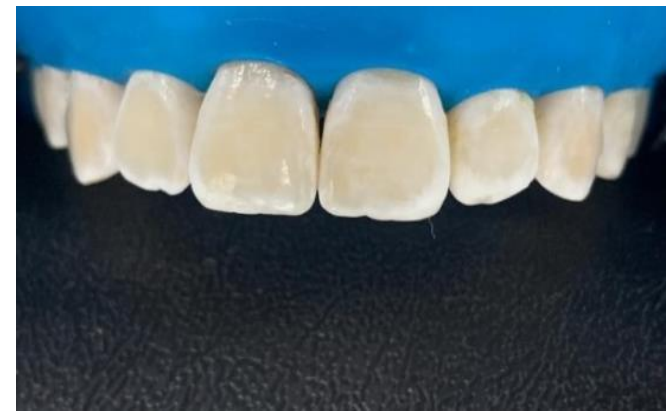

Figura 6: Aspecto clínico após a microabrasão. 


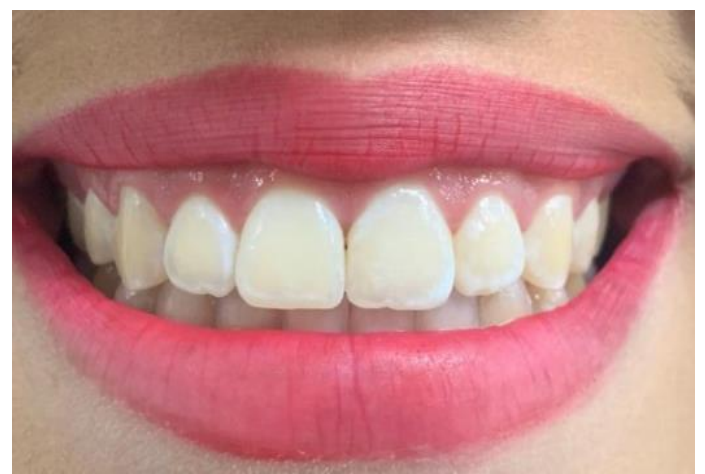

Figura 7: Aspecto clínico após a microabrasão.

Após a profilaxia com pedra pomes e água foram realizadas a tomada de cor utilizando escala Vita, na qual foi selecionada a cor B1 para incisivos centrais e laterais e A3,5 para caninos e pré-molares (Figura 8),em seguida foi feito o isolamento relativo e aplicação da barreira gengival (Top Dam®; FGM Produtos odontológicos, Joinville, SC, Brasil) com intuito de proteger a gengiva do gel clareador, posteriormente foi feito a aplicação deste, respeitando a manipulação, a forma de usar e o tempo segundo o fabricante (Figura 9).

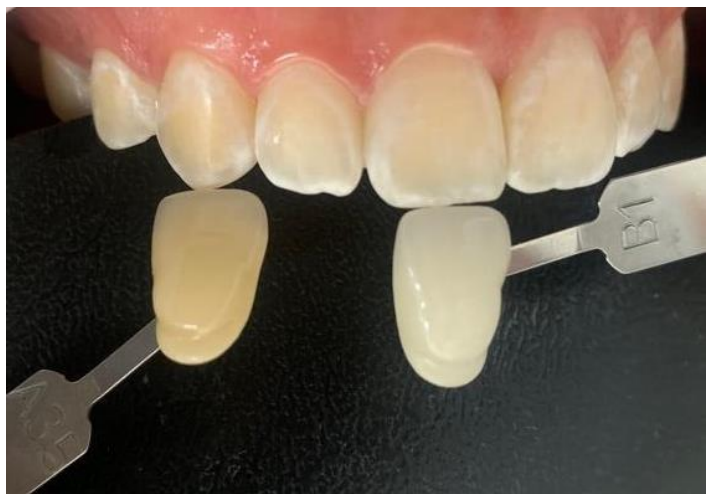

Figura 8. Tomada de cor com auxílio da escala de cor, definindo a cor B1 para incisivos centrais e laterais e A3,5 para caninos e pré molares.

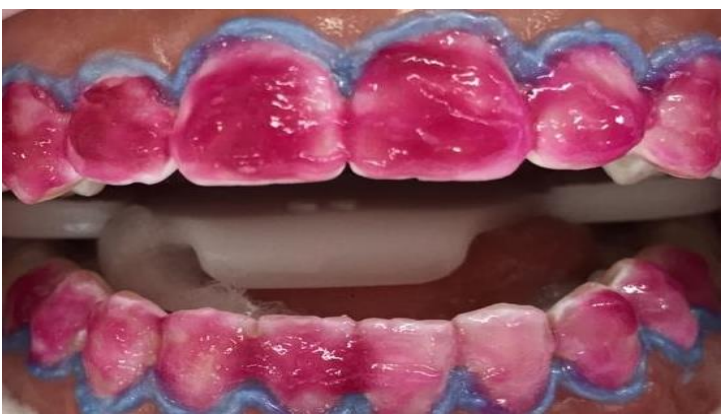

Figura 9. Aplicação da barreira gengival e gel clareador (peróxido de hidrogênio a 35\%).

Ao final das sessões foi removida a barreira gengival com uma sonda exploradora, o polimento com disco de feltro impregnado com pasta diamantada foi realizado e aplicação tópica de flúor neutro $2 \%$. Após as duas sessões pode-se observar um clareamento generalizado em todos os dentes que foram submetidos ao tratamento, foi realizada a tomada de cor final com auxílio da escala Vita, na qual foi evidenciado o sucesso do protocolo realizado (Figuras 10, 11 e 12).

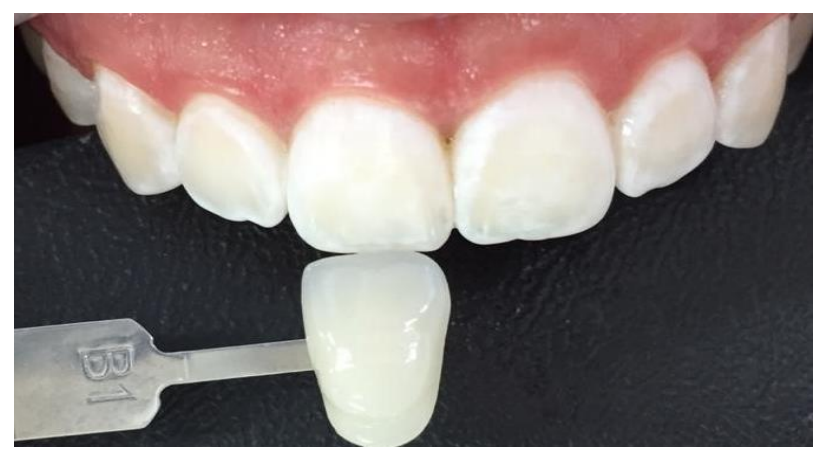

Figura 10: Tomada de cor final após o clareamento.

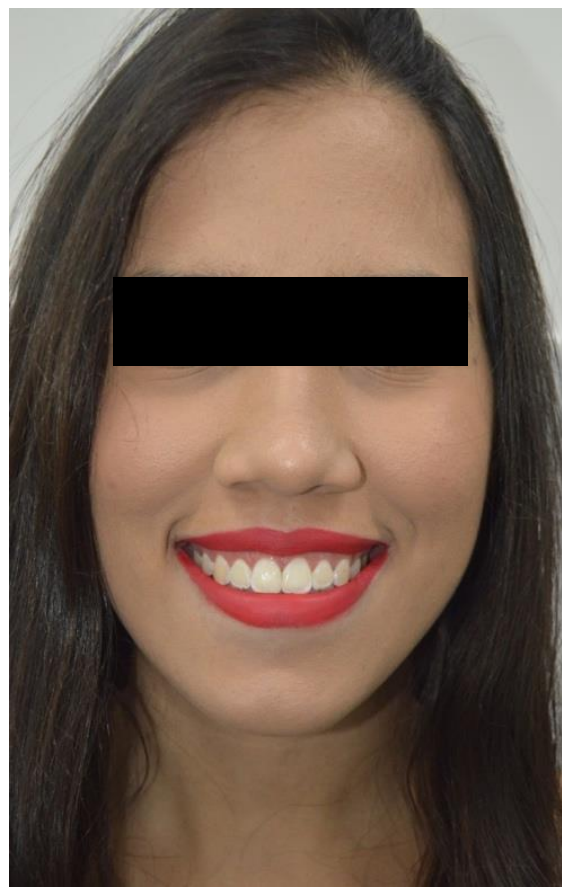

Figura 11: Antes dos tratamentos realizados.

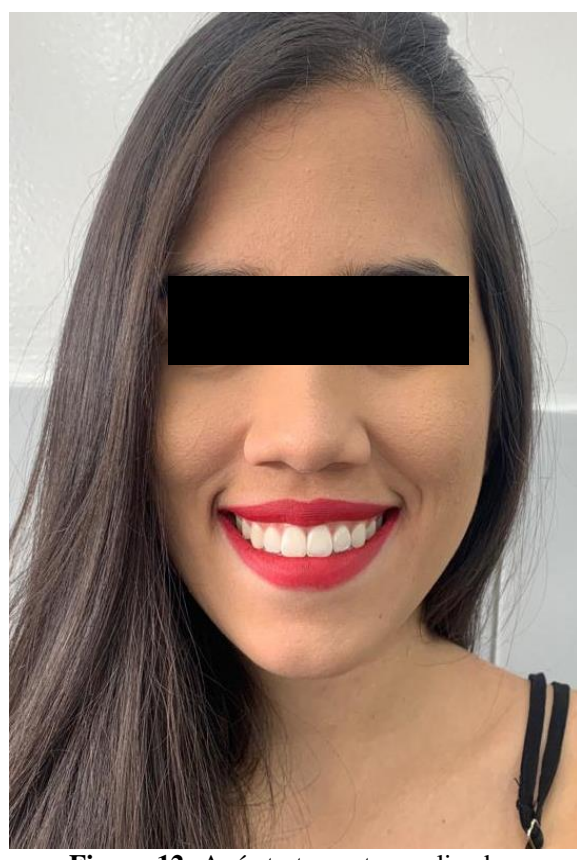

Figura 12: Após tratamentos realizados.

DISCUSSÃO

A fluorose dental ocorre quando há ingesta do flúor de forma contínua durante o período de formação dos dentes, causando manchas opacas, amareladas ou amarronzadas, deixando a superfície 
do esmalte hipomineralizada e microporosa. Sua gravidade está associada a quantidade e a duração da ingesta do flúor ${ }^{6}$. Estes manchamentos podem ser tratados de diversas formas ${ }^{5}$, desde tratamentos mais invasivos, como por exemplo: facetas diretas ou indiretas e lentes de contato, ou através de protocolos minimamente invasivos como, por exemplo: a microabrasão e o clareamento dental, implicando um menor desgaste da estrutura dentária sadia.

Em casos mais leves de fluorose, as técnicas mais utilizadas são a microabrasão ou a associação desta ao clareamento dental ${ }^{7}$. Porém, dependendo da coloração e profundidade das manchas, podem surgir limitações, por necessitar de um desgaste maior na qual serão realizadas restaurações estéticas ${ }^{8}$. A seleção do tratamento é dependente do aspecto clinico, profundidade e da severidade das manchas ${ }^{9}$. No entanto, é crescente a busca por procedimentos que solucionem os quesitos de estética e função, e que, possuam a mínima invasão e desgaste na estrutura dental ${ }^{1}$. No presente relato de caso clínico houve indicação da associação das técnicas de microabrasão e clareamento dentário.

A microabrasão é uma importante técnica conservadora, esta remove apenas uma camada superficial de esmalte pela ação conjunta de um agente erosivo (ácido fosfórico ou ácido clorídrico) e um agente abrasivo (pedra pomes ou carbeto de silício) $^{5}$. Estudos comprovam que esta técnica remove até $100 \mu \mathrm{m}$ superficialmente ao esmalte dentário ${ }^{6}$. No que diz respeito ao desgaste do esmalte dental, estudos de microscopia óptica realizado com diferentes grupos de materiais mostram que o ácido fosfórico a $37 \%$ e pedra pomes apresentaram um menor desgaste quando comparado ao ácido clorídrico a $18 \%$ e pedra pomes ${ }^{10}$.

A pasta utilizada no presente estudo foi o ácido fosfórico associado à pedra pomes, pois é uma boa opção, de fácil acesso aos profissionais, além de apresentar um menor desgaste da superfície dental, quando comparado a outros ácidos. Sendo uma técnica que também apresenta um baixo custo, fácil execução e com ótimos resultados estéticos imediatos.

Ao término de cada sessão de microabrasão o esmalte dental é polido com discos de feltro associado a pasta diamantada e tratado com flúor tópico em gel por 1 minuto, com finalidade de ajudar na remineralização e passando assim a apresentar uma lisura e brilho ${ }^{7,8}$. Tornando desta forma a superfície mais mineralizada e densamente compactada e resistente, com uma textura superficial favorável, diminuindo a aderência de bactérias a estrutura dental ${ }^{5}$.

Após ser finalizada esta etapa, foram eliminadas as manchas surperficiais dos dentes, e decorrente a isso a cor amarelada da dentina tornouse mais evidente ${ }^{11}$. O clareamento dental foi realizado por duas sessões em consultório com peróxido de hidrogênio a 35\% após 15 dias da finalização da microabrasão. Tempo, necessário para que haja uma remineralização completa da surperfície do esmalte abrasionado $^{8}$.

O clareamento dental não causa grandes danos ao esmalte microabrasionado, não influenciando na dureza e rugosidade superficial dos dentes. No entanto, estudos mostram que o aumento da rugosidade e redução da microdureza, são quesitos que estão em discussão ${ }^{12}$.Todavia, essas alterações tornam-se minimizadas pela ação do flúor e da saliva, ambos com efeito remineralizador ${ }^{12}$.

\section{CONSIDERAÇÕES FINAIS}

Quando bem indicados, tratamentos minimamente invasivos ou a associação destes, devem ser a primeira escolha para remoção de manchas superficiais, tendo em vista a facilidade da técnica, seu baixo custo quando comparado a procedimentos restauradores diretos e indiretos, além de preservar a estrutura dentária. Após a realização da microabrasão associada ao clareamento com peróxido de Hidrogênio a $35 \%$, pode-se observar excelentes resultados, de forma que a estética dentária da paciente foi reestabelecida.

\section{REFERÊNCIAS}

1. Catelan A, Bertoldo CES, Pini NP, Miranda DA, Lovadino JR, Aguiar FHB. Microabrasão do esmalte: comparação de técnicas através de relatos de casos clínicos. Rev dental press estét. 2012;9(3):78-86.

2. Bosquiroli V, Ueda JK, Baseggio W. Fluorose dentária: tratamento pela técnica da microabrasão associada ao clareamento dental. UFES Rev. Odontol. 2006;8(1):60-5.

3. Bevilacqua FM, Sacramento T, Felício CM. Amelogênese imperfeita, hipoplasia de esmalte e fluorose dental - revisão de literatura. Uniara. 2010;13(2):136-48.

4. Pinto VG. Saúde bucal coletiva. 6. ed. São Paulo: Santos; 2013.

5. Hermes SR. Microabrasão do esmalte dental para tratamento de fluorose. RGO Rev gaúch odontol. 2013;61(supl 1):427-33.

6. Castro ALS, Mendes CMC. Microabrasão e clareamento em dentes com fluorose: relato de um caso clínico. Rev Ciênc Méd Biol. 2014; 13(3):403-8.

7. Marson FB, Sensi LG, Araújo FO. Clareamento dental associado à microabrasão do esmalte para remoção de manchas brancas no esmalte. $\mathrm{R}$ Dental Press Estét. 2007;4(1):89-96.

8. Carvalho SRV, Nunes FEO, Soares CEO, Matuda LSA, Feitosa DAS. Microabrasão e clareamento dental no tratamento de manchas brancas sugestivas de fluorose. J Clin Dent Res. 2018;15(1):95-103. 
9. Oliveira LMX, Novaes-Júnior JB, Barreiros ID, Paiva SM, Martins CC. Tratamento de fluorose dentária moderada com a técnica de microabrasão de esmalte com ácido clorídrico $6 \%$ e carbeto de silício: relato de caso clínico. Arq Odontol. 2014;50(3):142-48.

Mendes RF, Mondelli J, Freitas CA. Avaliação da quantidade de desgaste do esmalte dentário submetido à microabrasão. Rev FOB. 1999;7(1/2):35-40.

10. Freitas ESP, Diogo EF, Roselino PL. Microabrasão do esmalte como tratamento conservador da fluorose dental. Revista Científica da Universidade de Franca. 2006;6(1):41-6.

11. Cordeiro RG, Torno V. Tratamentos estéticos e conservadores para a fluorose dental. Rev Fac Odontol Lins. 2012;21:47-51.

\section{CONFLITO DE INTERESSES}

Os autores declaram não haver conflitos de interesse.

\section{AUTOR PARA CORRESPONDÊNCIA}

\section{Diala Feitosa}

Departamento de Odontologia

Centro Universitário Doutor Leão Sampaio

Av. Maria Leticia Leite Pereira s/n - Lagoa Seca

63040-405 Juazeiro do Norte - CE, Brasil

Email: dialafeitosa@gmail.com

Submetido em 12/12/2019

Aceito em 18/03/2020 